\title{
Effect of Fibre Orientations on Damping and Vibration Characteristics of Basalt Epoxy Composite Laminates
}

\author{
Ömer Yavuz Bozkurt, Mehmet Bulut, Özkan Özbek \\ Mechanical Engineering/Gaziantep University \\ Gaziantep University Mechanical Engineering Department, Gaziantep, Turkey \\ First.oybozkurt@gantep.edu.tr; Second.mbulut@gantep.edu.tr; Third.ozkanozbek@gantep.edu.tr
}

\begin{abstract}
Damping and vibration characteristics of basalt epoxy fibre-reinforced composite laminated materials have been investigated with respect to the effect of fibre orientations. Four symmetric laminates having $\left[(0 / 90)_{4}\right]_{\mathrm{S}}$, $\left[(15 /-75)_{4}\right]_{\mathrm{S}}$, $\left[(30 /-60)_{4}\right]_{\mathrm{S}}$ and $\left[(45 /-45)_{4}\right]_{\mathrm{S}}$ fibre orientation angles were prepared using plain weave basalt fabrics as reinforcement. The dynamic modal analysis was performed to determine dynamic characteristics of the composite laminates. Using half power band-width method, the damping properties were deduced from vibration response envelope curve. Loss modulus, storage modulus and damping ratio of the structures were also determined. It was observed that damping and vibration characteristics of the composite samples were strongly affected by the fibre orientation of basalt/epoxy composite. The increase in angle of fibre orientation from $0^{\circ}$ to $45^{\circ}$ resulted in a decrease in natural frequencies and an increase in damping ratios.
\end{abstract}

Keywords: damping, vibration, basalt, composite

\section{Introduction}

In recent years, because of their improved and better characteristics, the use of the fibre reinforced composite laminated materials have extensively increased in structural applications. The properties of fibre-reinforced composite materials depend on several parameters such as material of fibre and matrix, curing process, fibre orientation, stacking sequence, inherent lamina and laminate level flaws introduced during the manufacturing process. Nevertheless, fibres are the primary factors controlling the properties of fibre-reinforced composite materials. Due to this, there have been a continual effort to use new stiff, strong, lightweight, low-cost and eco-friendly fibres in composite materials.

One of the exciting new fibre materials is basalt fibre. Basalt fibre is an eco-friendly material obtained from basalt. With its unique properties, basalt fibre is qualifies as a material for the production of fibre reinforced polymer composites. Over the years, several studies have been dedicated to the determination of mechanical properties of the basalt fibre reinforced composite materials. Fiore et al. [1] explored the mechanical, chemical and thermal performance of basalt fibre reinforced composite laminates. Czigány [2] investigated the contribution of basalt fibres on mechanical behaviours of hybrid fibre reinforced polyethylene composites. Lopresto et al. [3] presented the mechanical performance comparisons of plastic composites reinforced with basalt fibre and glass fibre. Cao et al. [4] presented the tensile properties of hybrid carbon/glass and hybrid carbon/basalt composites at different temperatures to show the thermal performance of the composites. Ary Subagia et al. [5] studied the effect of stacking sequences on the flexural properties of hybrid basalt/carbon composite laminates. Petrucci et al. [6] studied mechanical performance of different hybrid laminates based on basalt fibre for inner core material, and glass, flax and hemp fibre for outer layers for symmetrical configuration. Sarasini et al. [7] investigated the quasi-static mechanical properties and low velocity impact behaviour of carbon/basalt laminates and the effects of hybridization on those properties. Petrucci et al. [8] examined the impact and flexural postimpact behavior of ternary hybrid composites based on epoxy resin reinforced with basalt, flex, hemp and glass fibres. Dorigato and Pegoretti [9] investigated the hybridization effect on the flexural and impact properties of carbon/basalt fibre reinforced composite laminates. All these studies have reported the tensile, compressive, flexural, impact and thermal properties of basalt fiber reinforced composite laminates.

Damping capacity which measures the ability of vibration energy absorption is another unique characteristic of fibre-reinforced composites. It is used for reducing the transmission of noise and vibrations to neighbouring structures [10]. Several researchers studied dynamic behavior of hybrid composite laminates investigating hybridization effects. Vannan 
and Vizhian [11] investigated the effect of temperature on damping characteristics of aluminium alloy/basalt short fibre metal matrix composites containing various amounts of short fibres. An increase in loss modulus and damping capacity, and a decrease in storage modulus were reported with increasing temperature. It was also reported that increase in short basalt fibre contents increased both the loss modulus and storage modulus. Yan et al. [12] investigated stability dynamic response of basalt woven composite laminates. They concluded that the magnitude and phase behaviour of basalt fibre composites were quite different under the quasi-static and high strain rate loading conditions. Baştürk et al. [13] analysed nonlinear damped vibration response of a Kevlar/E-glass hybrid composite plates subjected to the blast load. The role of amplitude of the damping ratio on the deflection and the frequencies of the plate were noticed.

Based on the above literature study, the characteristics of basalt fibre reinforced composite laminates under impact, tensile and compressive loading have been investigated by several researchers. To the authors' knowledge, there is only one open literature available on damping and vibration characteristics of basalt fibre reinforced epoxy composite. The goal of the current study is to determine the damping and vibration behaviour of basalt/epoxy composite laminates, and the evaluation of the effect of fibre orientations on the damping and vibration characteristics.

\section{Materials and Methods}

Plain weave bramid fibre with areal density of $200 \mathrm{~g} / \mathrm{m}^{2}$ were used as reinforcement in the lamina. Epoxy resin (MOMENTIVE-MGS L285) with hardener (MOMENTIVE-MGS L285) in the ratio of 100:40 was used in the common matrix. Four symmetrical laminates having $\left[(0 / 90)_{4}\right]_{S}$, $\left[(15 /-75)_{4}\right]_{S},\left[(30 /-60)_{4}\right]_{S}$ and $\left[(45 /-45)_{4}\right]_{S}$ fibre angles were prepared to study the effects of fibre orientation (Table 1). The fibre volume fractions of laminates were the same in all specimens and were approximately equal to $56 \%$. Laminated fabrics with dimensions of $300 \mathrm{~mm} \times 300 \mathrm{~mm}$ were prepared using vacuum assisted resin transfer molding technique. The vacuum applied was $700 \mathrm{~mm} \mathrm{Hg}$ for $8 \mathrm{~h}$. then, the composite laminates were left to a post cure period at room temperature. Thickness of the composite laminates were measured as $\mathrm{t}=1.7 \pm 0.02 \mathrm{~mm}$.

Table 1: Conifgurations of produced spec mens having symmetrical stacking sequences.

\begin{tabular}{|c|c|}
\hline Symmetrical configurations & Naming \\
\hline$\left[(0 / 90)_{4}\right]_{\mathrm{S}}$ & $\left(\mathrm{B}_{8}\right)^{0}$ \\
\hline$\left[(15 /-75)_{4}\right]_{\mathrm{s}}$ & $\left(\mathrm{B}_{8}\right)^{15}$ \\
\hline$\left[(30 /-60)_{4}\right]_{\mathrm{s}}$ & $\left(\mathrm{B}_{8}\right)^{30}$ \\
\hline$\left[(45 /-45)_{4}\right]_{\mathrm{s}}$ & $\left(\mathrm{B}_{8}\right)^{45}$ \\
\hline
\end{tabular}

\subsection{Vibration Tests}

Dynamic characteristics of composite laminates were measured using an experimental set-up according to ASTM E756 [14] as shown in Fig. 1. A general purpose PCB 352C03 ceramic shear ICP $®$ accelerometer for output signal acquisition, a PCB 086C03 general purpose modal impact hammer for stimulus force signal and a National Instrument product NI 9234 data acquisition device with LABVIEW software were used in the experiments. The coupons with dimensions of $200 \mathrm{~mm} \times 20 \mathrm{~mm}$ were cut from the composite laminates using CNC router, and samples were clamped by supports (Fig. 1 (c)).

To achieve dynamic characteristics, the prepared composite samples were excited using the impact hammer. Time dependent acceleration response of the specimen was measured by the applying the impact hammer and recording the acceleration. Fast Fourier Transform (FFT) was applied to determine the magnitude versus frequency depended responses. Frequency responses were extracted within the constant frequency range from 0 to $800 \mathrm{~Hz}$. Five specimens were prepared for each laminate configuration and three vibration tests were recorded for each specimen. 


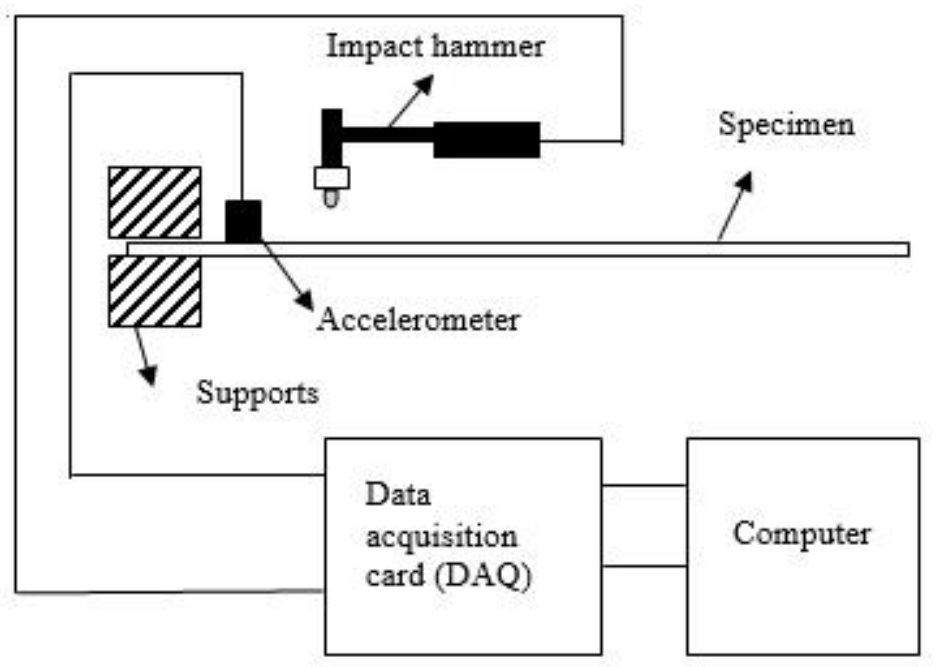

a)

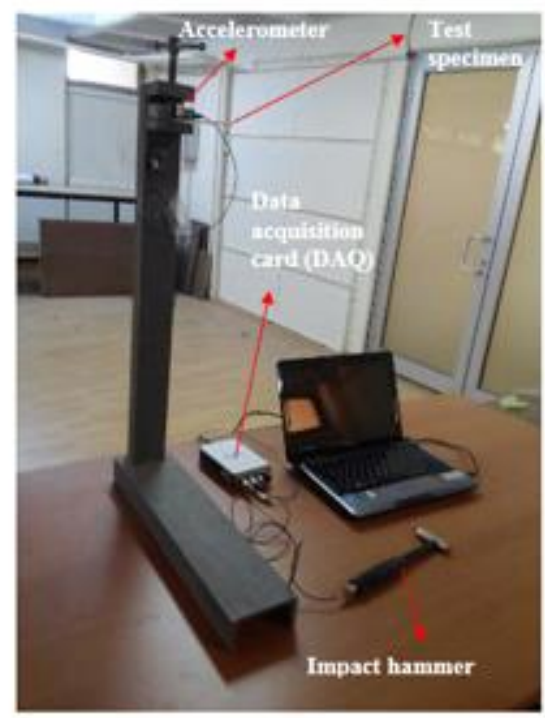

b)

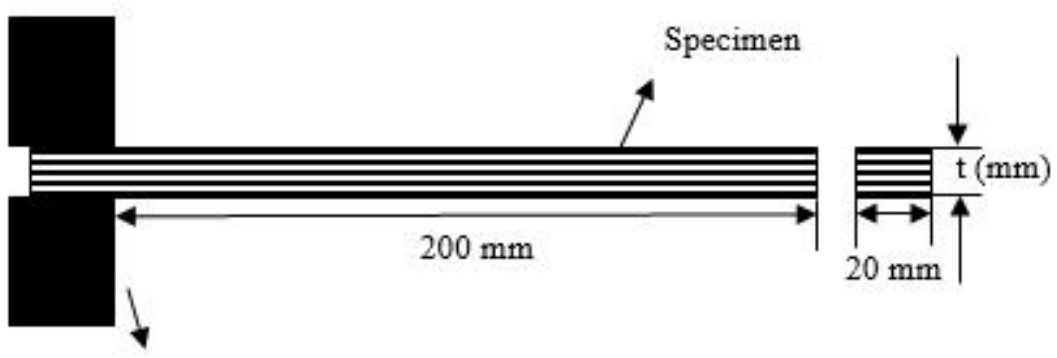

Supports

c)

Fig. 1: Vibration test set-up. (a) Sketch of vibration test mechanism, (b) Overall view of vibration test set-up, (c) Test specimens with dimensions in the frame.

\subsection{Damping Ratios}

In order to measure damping responses, half power band-width method was used for first natural frequency mode of the specimen. The damping ratio was measured according to the half-bandwidth method as shown in Fig. 2, according to Eq. (1)

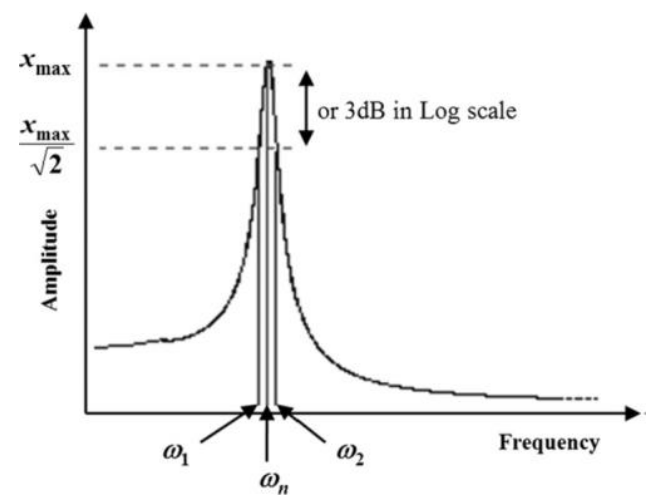

Fig. 2: Half power band-width method. 


$$
\xi=\frac{\omega_{2}-\omega_{1}}{2 \cdot \omega_{n}}
$$

Where $\omega_{1}, \omega_{2}$ are the bandwidth, $\omega_{n}$ is the natural frequency of first mode, and $\xi$ is the damping ratio. The storage modulus $\left(E^{\prime}\right)$ of samples was obtained using Eq. (2).

$$
\omega_{1}=\frac{1.875^{2}}{2 \cdot \pi \cdot L^{2}} \sqrt{\frac{E^{\prime} \cdot I}{\rho \cdot A}}
$$

where $\rho$ is density of the beam, $A$ is the cross-section of the beam, $I$ is the moment of inertia of the given crosssection of beam, $E^{\prime}$ is the storage modulus, $L$ is the free length of the beam and $\omega_{1}$ is the natural frequency of first mode. Similarly, loss modulus $\left(E^{\prime \prime}\right)$ of the beam can be found using the following relationship between loss and storage modulus.

$$
E^{\prime \prime}=E^{\prime}(\omega) \cdot \tan (\delta)=2 \cdot E^{\prime}(\omega) \cdot \xi(\omega)
$$

\section{Results and Discussions}

From the vibration test results, the frequency response curves were plotted as shown in Fig. 3. The first and second mode natural frequency values are given in Table 2. It is observed that first mode natural frequency is clearly dominant for all samples. The natural frequency decreased while maximum amplitude increased with increasing fibre angle. This is explained by the alignment of fibres in the lamina which contributes to the stiffness of the specimens. In addition, while the fibre angle increases from $0^{\circ}$ to $45^{\circ}$, stiffness of the specimen along the longitudinal direction decreases. Due to this reason, reduction of stiffness resulted in decrease of natural frequency based on equation 2. However, damping ratio increases while fibre angle increases from $0^{\circ}$ to 45 . This may be attributed the reduction of vibration energy dissipation along the longitudinal direction. Similarly, Liang et al. [15] indicated that the increase of effective damping could be cause a reduction of energy dissipated and responses by means of amplitudes.

Table 2: Damping and natural frequency values

\begin{tabular}{|c|c|c|c|c|c|c|c|}
\hline $\begin{array}{c}\text { Fibre } \\
\text { angle }\end{array}$ & $\begin{array}{c}\text { First } \\
\text { mode } \\
\mathbf{( H z )}\end{array}$ & $\begin{array}{c}\mathbf{A}_{\mathbf{1}} \\
\mathbf{( g / N )}\end{array}$ & $\begin{array}{c}\text { Second } \\
\text { mode } \\
\mathbf{( H z})\end{array}$ & $\begin{array}{c}\mathbf{A}_{\mathbf{2}} \\
\mathbf{( g / N )}\end{array}$ & $\begin{array}{c}\text { Damping } \\
\text { ratio }\end{array}$ & $\begin{array}{c}\text { Storage } \\
\text { modulus } \\
(\mathbf{G P a})\end{array}$ & $\begin{array}{c}\text { Loss } \\
\text { modulus } \\
(\mathbf{G P a})\end{array}$ \\
\hline $\mathbf{0}^{\circ} / \mathbf{9 0}^{\circ}$ & 33.79 & 89.21 & 199.68 & 118.06 & 0.348 & 18.8 & 13.1 \\
\hline $\mathbf{1 5}^{\circ} / \mathbf{- 7 5}^{\circ}$ & 30.72 & 96.84 & 177.15 & 116.47 & 0.390 & 14.3 & 11.2 \\
\hline $\mathbf{3 0}^{\circ} / \mathbf{- 6 0}^{\circ}$ & 28.67 & 87.36 & 169.98 & 109.00 & 0.408 & 11.6 & 9.4 \\
\hline $\mathbf{4 5}_{\mathbf{- 4 5}}$ & 26.62 & 81.22 & 163.84 & 116.90 & 0.473 & 9.6 & 9.1 \\
\hline
\end{tabular}

$\mathrm{A}_{1}$ : Maximum Amplitude of First Mode; $\mathrm{A}_{2}$ : Maximum Amplitude of Second Mode

Fig. 4 illustrates the influence of fibre angle resulting from the displacement versus time records. Amplitude-time decaying curves were recorded within the same time interval ( 2 seconds) in order to compare damping properties of samples. It can be concluded that the increase of fibre angle of basalt-epoxy composite laminates from $0^{\circ}$ to $45^{\circ}$ decreased the natural frequency while increasing the damping ratios. 


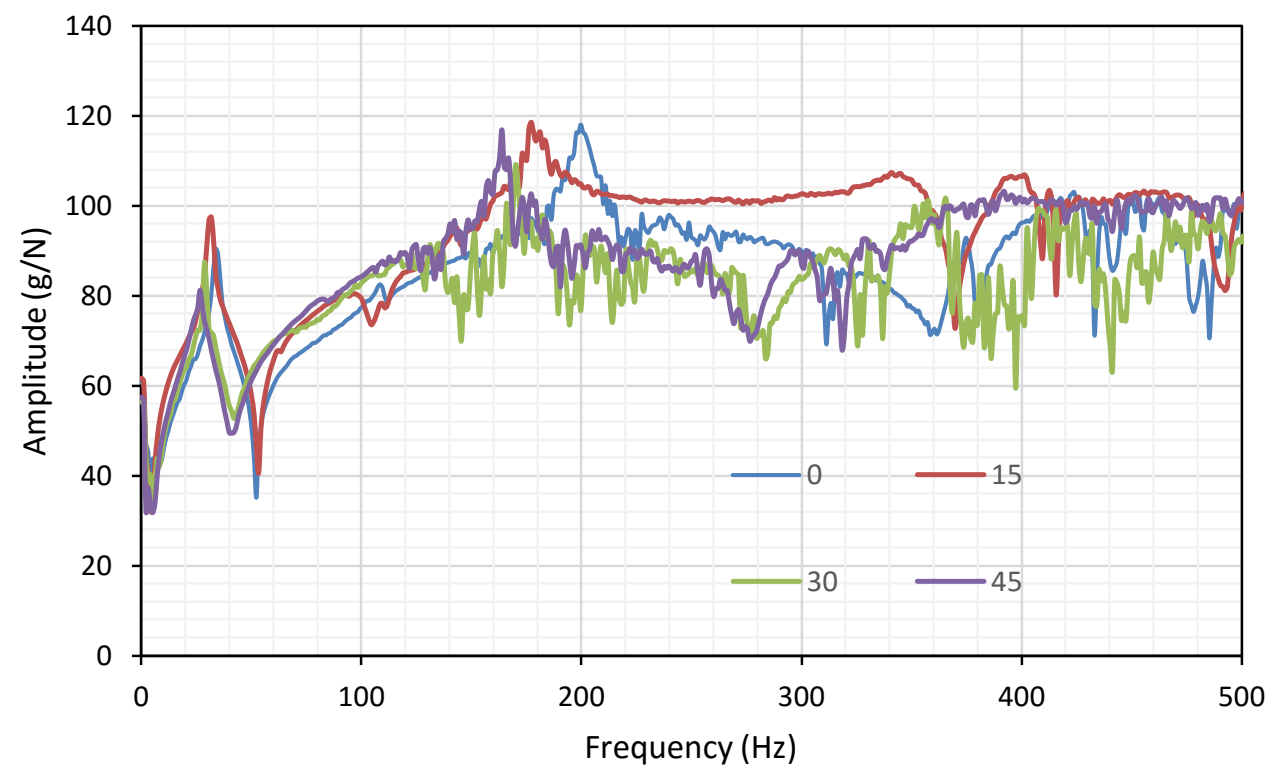

Fig. 3: Frequency responses of samples.
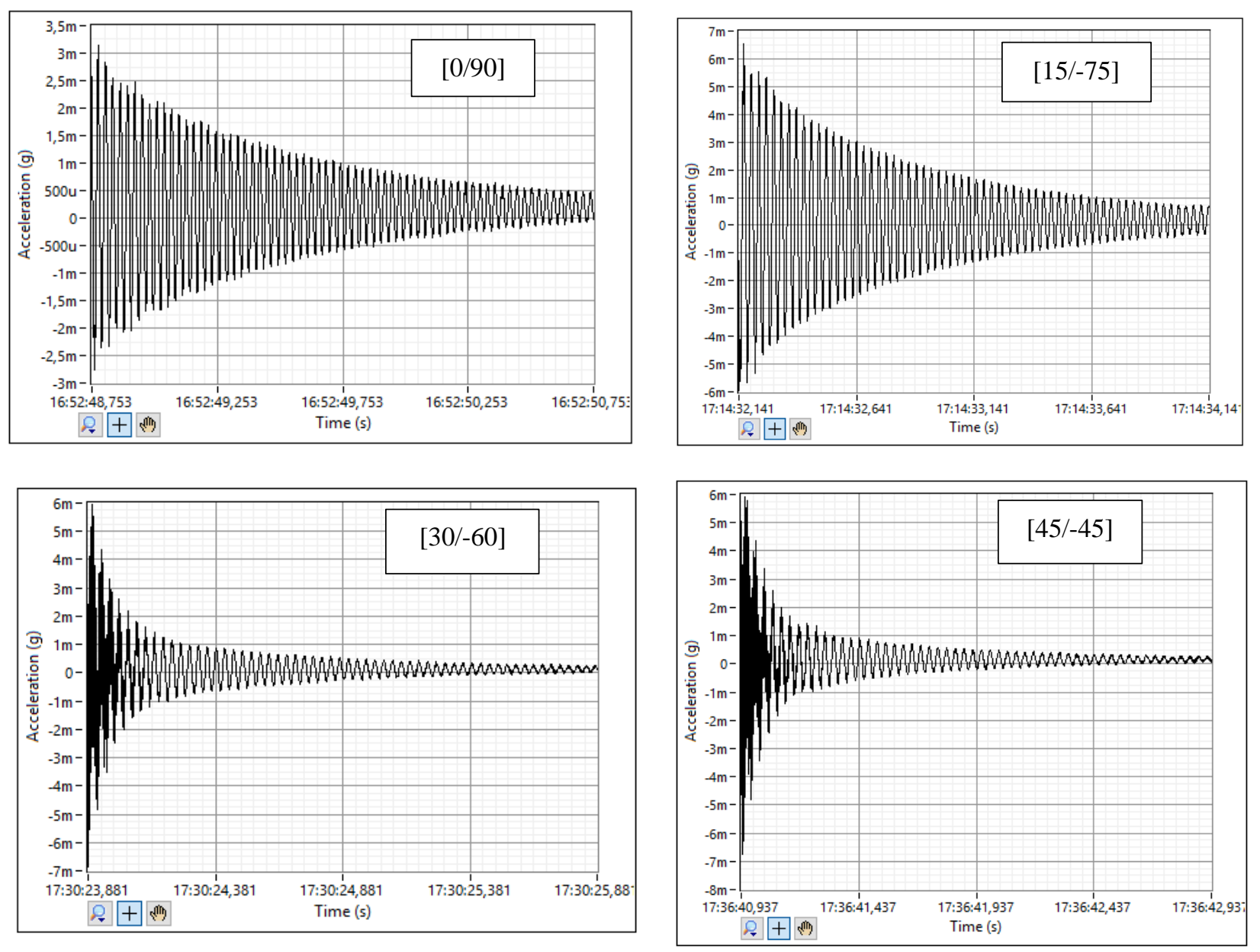

Fig. 4: Time dependent acceleration responses of samples. 


\section{Conclusion}

Damping and vibration characteristics of basalt/epoxy composite laminates were determined and the effect of fibre orientation was evaluated. Using the logarithmic decrement method, the damping properties were obtained from vibration response envelope curves. The main conclusions from this study can be summarized as follows:

- damping and vibration characteristics of the composite samples are strongly affected by the fibre orientation of basalt/epoxy,

- the increase in angle of fibre orientation from $0^{\circ}$ to $45^{\circ}$ resulted in a decrease in natural frequency,

- the laminates having higher fibre orientation angle had higher damping ratios,

- the storage and loss moduli decrease with increasing fibre orientation angle,

Finally, the results suggest that it can be possible to obtain a desired damping and vibration capability by altering the orientation angles of basalt fibres.

\section{References}

[1] V. Fiore, T. Scalici, G. Bella, and A. Valenza, "A review on basalt fibre and its composites," Composites Part B, vol. 74, pp. 74-94, 2015.

[2] T. Czigany, "Special manufacturing and characteristics of basalt fibre reinforced hybrid polypropylene composites: Mechanical properties and acoustic emission study," Composite Science and Technology, vol. 66, pp. 3210-3220, 2006.

[3] V. Lopresto, C. Leone, and I. Iorio, "Mechanical characterisation of basalt fibre reinforced plastic," Composites Part B: Engineering, vol. 42, pp. 717-723, 2011.

[4] S. H. Cao, Z. S. Wu, and X. Wang, "Tensile properties of CFRP and hybrid FRP composites at elevated temperature," J. Compos. Mater., vol. 43, pp. 315-330, 2009.

[5] I. D. G. Ary Subagia, Y. Kim, L. D. Tijing, C. S. Kim, and H. K. Shon, "Effect of stacking sequence on the flexural properties of hybrid composites reinforced with carbon and basalt fibers," Compos. B. Eng., vol. 58, pp. 251-258, 2014.

[6] R. Petrucci, C. Santulli, D. Puglia, F. Sarasini, L. Torre, and J. M. Kenny, "Mechanical characterisation of hybrid composite laminates based on basalt fibres in combination with flax, hemp and glass fibres manufactured by vacuum infusion," Materials and Design, vol. 49, pp. 728-735, 2013.

[7] F. Sarasini, J. Tirillò, L. Ferrante, M. Valente, T. Valente, L. Lampani, P. Gaudenzi, and S. Cioffi, "Drop-weight impact behaviour of woven hybrid basalt-carbon/epoxy composites," Composites Part B: Engineering, vol. 59, pp. 204-220, 2014.

[8] R. Petrucci, C. Santulli, D. Puglia, E. Nisini, F. Sarasini, J. Tirillò, L. Torre, G. Minak, and J. M. Kenny, "Impact and post-impact damage characterisation of hybrid composite laminates based on basalt fibres in combination with flax, hemp and glass fibres manufactured by vacuum infusion," Composites: Part B, vol. 69, pp. 507-515, 2015.

[9] A. Dorigato and A. Pegoretti, "Flexural and impact behaviour of carbon/basalt fibers hybrid laminates," Journal of Composite Materials, vol. 48, pp. 1121-1130, 2014.

[10] S. Adali and V.E. Verijenko, "Optimum stacking sequence design of symmetric hybrid laminates undergoing free vibrations," Composite Structures, vol. 54, pp. 131-138, 2001.

[11] S. E. Vannan, S. P. Vizhian, and R. Karthigeyan, "Investigation on the Influence of Basalt Fiber on Thermal properties of A17075/ Basalt Fiber Metal Matrix Composites," Procedia Engineering, vol. 97, pp. 432-438, 2014.

[12] J. Yan, B. Gu, and B. Sun, "Dynamic response and stability of basalt woven fabric composites under impulsive compression," Journal of Reinforced Plastics and Composites, vol. 32, pp. 137-144, 2013.

[13] S. Baştürk, H. Uyanık, and Z. Kazancı, "Nonlinear damped vibrations of a hybrid laminated composite plate subjected to blast load," Procedia Engineering, vol. 88, pp. 18-25, 2014.

[14] ASTM E756, Standard Test Method for Measuring Vibration-Damping Properties of Materials. West Conshohocken, PA: ASTM International, 2010.

[15] Z. Liang, G. C. Lee, L. G. F. Dargush, and J. Song, Structural Damping, Applications in Seismic Response Modification. Boca Raton: CRC Press, Taylor \& Francis Group, 2012. 